\title{
Why does on-farm storage fail to mitigate price volatility?
}

\author{
Elodie Maître d'Hôtel ${ }^{1}$ and Tristan Le Cotty ${ }^{1}$
}

${ }^{1}$ CIRAD, France

\begin{abstract}
We analyze the role of farm stock management on price volatility under liquidity constraints and heterogeneous price expectations. In commodity markets, speculative behaviors by stockholders tend to reduce price volatility, but this is not the case in certain agricultural markets, where speculation by farmers regarding decisions to sell or store grain are subject to liquidity constraints and heterogeneous price expectations. Like stockholders, most farmers sell grain if they expect a price drop in the near future, but unlike stockholders, they are not necessarily able to purchase grain if they expect a price increase in the next period. Heterogeneous price expectations can also lead to suboptimal storage decisions, further increasing price volatility. For these reasons, the storage management behavior of farmers often fails to mitigate price drops in the way that speculation by stockholders does. We merge historical data on maize prices and household storage collected in Burkina Faso in order to build a dynamic panel over the 2005-2012 period. We show that carry-over from one season to the next is associated with unexpected price drops during the preceding lean season and that carry-over is associated with more frequent unexpected price drops following the subsequent post-harvest season.
\end{abstract}

Keywords : storage, price volatility, anticipation errors, maize, Africa

JEL codes : Q18 Q13 Q12 Q11

Corresponding author elodie.maitredhotel@ cirad.fr

This article has been accepted for publication and undergone full peer review but has not been through the copyediting, typesetting, pagination and proofreading process, which may lead to differences between this version and the Version of Record Please cite this article as doi: 10.1111 /agec. 12396 
Received 30 March, 2016; received in revised form 26, April 2017; accepted 10 May, 2017

No Data Appendix Available Online

\section{Introduction}

In developing countries, decisions regarding farm storage are subject to certain constraints that impact price behaviours and this impact is inadequately described by existing commercial stock management theory. The standard relation between stocks and price volatility is described in the competitive storage model (Deaton and Laroque, 1992). Although several studies have relaxed the restrictive assumptions of this model, they have not done so in a way that describes the impact of farm storage and marketing decisions on price volatility in developing countries. To address this, we modify the Deaton and Laroque model in two ways: we introduce liquidity constraints and heterogeneous information about grain availability. These two factors play an important role in farmers' marketing decisions in Burkina Faso, and may explain why rural prices in developing countries do not exhibit the same patterns as international commodity prices.

Empirical observations that support the competitive storage model by Deaton and Laroque (1992) are characterized by two features: price series distributions always exhibit a positive skewness (upward price spikes are more frequent or have a greater magnitude than downward spikes) and almost always exhibit a positive kurtosis (the price distribution has greater peakedness than the normal distribution, for the same variance). These properties are attributed to the effect of storage in smoothing price shocks in general, and downward price 
shocks in particular. Deaton and Laroque build a storage model that generates simulated price series that are characterized by these two properties.

After analyzing 33 monthly maize price series arising from 33 marketplaces in Burkina Faso, however, we obtained 33 price distributions that do not exhibit these properties. Instead, kurtosis is frequently negative, which indicates that price fluctuations are greater in our distributions than in a normal distribution, and skewness is frequently negative in the post-harvest season, indicating either more frequent or more severe price drops than in a normal price distribution (see table 1 in section 5).

In this paper, we investigate whether these atypical price patterns may be related to liquidity constraints and heterogeneity in price expectations. To do so, we adapt the competitive storage model in order to analyze the role of farm storage on price volatility.

In section 2, we provide a background on the drivers of farm storage that have been studied in the literature to date. In section 3, we introduce a liquidity constraint and expectation errors in the competitive storage model and analyze how these factors modify storage decisions and price behavior over the course of a year. In section 4 , we describe our empirical strategy. Employing ARCH models and dynamic panel analysis over the 2005-2012 period, we combine original household and price data to test the role of farm storage on price volatility in local markets. In section 5 , we demonstrate that carry-overs are associated with unexpected price drops in the preceding year and that carry-over is associated with an increased frequency of unexpected price drops at the beginning of a new year.

\section{Background on farm storage}

Several analyses of the role of stockholder decisions on price dynamics have demonstrated that, in standard cases, storage management has a smoothing effect on price 
volatility (Wright, 2011). A key feature of this literature rests on the "buy low, sell high" principle (Gustafson, 1958), by which the optimal storage and sale of grain stocks tends to mitigate price shocks. This is at the root of the competitive storage model, originally applied to commodities that can be stored for more than a year and are subject to random production shocks (Gustafson, 1958; Deaton and Laroque, 1992; Cafiero, Bobenrieth, Bobenrieth, and Wright, 2011). Analyses of price series data (Deaton and Laroque, 1992; Bobenrieth, Wright, and Zeng, 2013; Serra and Gil, 2013), as well as simulations have given empirical support to this model (Deaton and Laroque, 1992; Frechette, 1999).

However, the scarcity of storage data series has limited the number of direct empirical tests of the relationship between storage and prices. Some have used monthly storage forecasts (Shively, 1996) or historical monthly prices as a proxy for storage data (Serra and Gil, 2013). At the macroeconomic level, there are results on the relationship between the stock level and price volatility ${ }^{1}$. At the domestic or infra-domestic level, the role of public storage on price volatility is also well documented (Barrett, 1997).We contend, however, that the relationship between farm storage and price volatility has not been modelled or empirically assessed. We ask, can the competitive storage model account for the price pattern observed in rural Burkina Faso, and if so, under what modifications?

A primary difference between commercial stockholders and farmers arises from the farmer's market participation issue. As a result of high transaction costs, farmers' sales prices may be inferior to their purchase prices (De Janvry, Fafchamps, and Sadoulet, 1991; Key, Sadoulet, and De Janvry, 2000; Bellemare and Barrett, 2006), which hinders their market

\footnotetext{
${ }^{1}$ It has been observed that periods with low stocks correspond to price spikes on world markets (Wright, 2011). When stocks are low, a small production or consumption shock can have large impacts on price because adjustments are characterized by greater inelasticity (Gilbert and Morgan, 2010)
} 
participation. Because of this, their reactions to price shifts are not as systematic as depicted in the competitive model. A price increase produces a sale only if the sales price rises above the farmer's shadow price, which is equal to the farmer's marginal utility for the grain. Prioritizing food security can also limit their willingness to sell even when prices are high (Saha and Stroud, 1994; Fafchamps, 1992; Kazianga and Udry, 2006). During the lean season, grain prices are generally high, and farmers have an incentive to sell grain; despite this, they may instead prefer to keep their grain in order to ensure family consumption until the next harvest, as possessing an adequate stock of grain prevents them from buying food when prices are high (Park, 2009). This seasonal pattern has been described in many African contexts (Saha and Stroud, 1994; Kazianga and Udry, 2006; Bellemare and Barrett 2006). However, the bounded market participation limits both sales and purchases, thus should not eliminate positive skewness of price distribution due the stock non-negativity constraint.

A second difference between commercial stockholder and small-scale farmers is the importance of liquidity constraints due to poor access to credit and low cash savings. Both the "buy low" and the "sell high" guiding principles at the core of the competitive storage model are unattainable for farmers whose liquidity comes from grain sales (Fackler and Livingston, 2002). Prices in Africa follow a cyclical pattern every year: grain prices are at their lowest level during the harvest season and then increase until the lean season when they reach their peak. The predictability of this price dynamic creates incentives to purchase grain during the harvest season and store it until the lean season in order to sell it at a high price. This strategy would attenuate price seasonality, but it does not in fact characterize the behavior of most farmers. Under strong liquidity constraints during the harvest season, farmers can satisfy their cash needs only by selling grain at low prices, contributing to further price decreases. This occurs at a time when, according to the competitive storage model, they "should" be buying grain instead. In this case, the storage-price relation is the opposite of that which is 
presented in the standard model and ultimately, farm storage may be better described by a "sell low, buy high" principle (Stephens and Barrett, 2011). This constraint to purchase could explain small or negative skewness of price distributions.

A third difference is that farmer price expectations may not obey standard assumptions. Farmers are heterogeneously informed, and it is likely that they also vary in their capacity to formulate price expectations based on the information available to them (Chavas, 2000). The standard notion of rational expectations rests on two assumptions: (i) perfect information about the present (uncertainty only exists in regard to future shocks) and (ii) uniform expectations (Muth, 1961; Deaton and Laroque, 1992). In this framework, agents use available information to derive optimal storage decisions and the only source of price volatility is random shocks to future harvests. These assumptions have been relaxed by several authors. In attempts to add "realism" to the analysis (Peterson and Tomek, 2005), the hypothesis of perfect information has been relaxed, generating the concept of bounded rational expectations and led to models of adaptive expectations ${ }^{2}$. These models lead to an endogenous source of price fluctuations, caused by expectation errors. Under this assumption, storage decisions may be non-optimal and reinforce, rather than mitigate, price fluctuations. Several models of endogenous price fluctuations that integrate storage strategies have been developed recently (Mitra and Boussard, 2012; Femenia, 2015; Berg, 2016) ${ }^{3}$. These models

\footnotetext{
2 The perfect information assumption regarding grain availability is less plausible in African villages because information on grain stocks is of strategic importance for food security. The reputational threat associated with having grain but refusing to help a hungry person is so strong that farmers have no choice but to help, that is, unless people believe they have virtually no grain at home. As a result of this social pressure, farmers tend to conceal their stock of grain, especially during the lean season. It is thus unlikely that farmers would be aware of the true level of stock in the village.

${ }^{3}$ Models with heterogeneous expectations, primarily used in finance, have also been developed in order to better fit actual price series data (Branch, 2004) and to assess the expectation learning process through experiments (Hommes, 2011). Theoretical work has shown that models that incorporate
} 
show that seasonal storage decisions increase the likelihood of chaotic price fluctuations (Mitra and Boussard, 2012), that storage subsidies may, on average, destabilize agricultural markets (Femenia, 2015), and that higher expected prices and resulting reductions in farm storage may increase volatility (Berg, 2016). Our paper is related to these three papers in that we analyze the impact of expectation errors on storage strategies and resulting price volatility. Nevertheless, our assumptions and methods are different: errors in our model arise from imperfect information on grain availability in the village, and we use real price and storage data $^{4}$ in order to provide an empirical measure of expectation errors and their effect on storage and prices. In the three mentioned models, with the exception of Mitra and Boussard (2012) who extend the model to include two seasons, each suboptimal production decision generates a price deviation from its equilibrium, implying that production decisions occur as frequently as observed price shifts. This cannot be the case in intra-annual models. In this paper, we assume that expectation errors are not caused by errors in production forecast, but by imperfect information on stock availability. We thus relax the assumption of rational expectations, according to which decision-makers know the current volume of aggregated stock.

\section{The seasonal dynamics of storage}

expectation error have the potential to account for greater volatility than perfect information models (Grandmont, 1998).

${ }^{4}$ Most of the research on endogenous factors contributing to price dynamics consists in developing theoretical models that are used to simulate price series that are as consistent as possible with the distribution of observed prices (Mitra and Boussard 2012, Berg 2016) as well as to simulate changes in the system (Femenia 2015).

This article is protected by copyright. All rights reserved. 
We introduce two aspects of farm storage into the standard competitive storage model: liquidity constraints and heterogeneous expectations ${ }^{5}$.

\subsection{A liquidity constraint in the competitive storage model}

In the Deaton and Laroque (1992) model, the profit from holding inventory $I_{t}$ from period $t$ to $t+1$ is given by:

$$
\left[\beta(1-\delta) E_{t} p_{t+1}\right] I_{t} ; \quad I_{t} \geq 0
$$

where $\beta$ is the discounting factor, $\delta$ is the stock spoilage rate, $p_{t}$ is the grain price at period $t$, and $E_{t}$ is the expectation conditional on information available at $t$, which is the amount of grain on hand at $t$. This amount is equal to harvest $z_{t}$ if there is harvest at $t$ plus the depreciated amount of grain that was stored during the previous period $(1-\delta) I_{t-1}$. Since $t$ is a monthly index in our framework, $z_{t}$ is equal to zero every month except for the month of harvest.

This model assumes that the stockholder can purchase grain without restriction ${ }^{6}$. In the case of a liquidity constraint, an agent expecting a price increase may not be able to purchase grain if this agent has nothing to offer but grain. Imposing a liquidity constraint in order to

\footnotetext{
${ }^{5}$ Other dimensions of farm stock management, such as consumption risks (Kazianga and Udry, 2006) or transaction costs (De Janvry, Fafchamps, and Sadoulet, 1991), may play a role in price volatility, but are not under the scope of this paper.

${ }^{6}$ Net buyers of grain are not included in the supply side of our model, but in the demand side. Since net buyers have some non-grain source of cash, they are not subject to the binding liquidity constraint described in our model. As in the competitive storage model (equation (9)), the demand for grain depends on present prices only, and thus does not impact volatility. This is a simplification of reality, as the demand of net buyers may also depend on their farm stock, price expectations, as well as irregular sources of income (e.g. animal sales, non-farm activities, family transfers), all of which may affect price volatility. Incorporating these elements would significantly increase the complexity of the model.
} 
account for the situation of most farmers in Burkina Faso, the model is modified by the addition of the following restriction

$$
I_{t} \leq(1-\delta) I_{t-1}+z_{t}
$$

Present stock is composed of previous period stock plus present harvest, if there is any. Farm stock can no longer increase between two periods without harvest ${ }^{7}$.

Restriction (2) reflects the absence of credit and savings, as well as alternative sources of cash. If alternative sources of income exist, the liquidity constraint either disappears or decreases. After maximizing profit, in the general case where the farmer has not already stocked out at $t-1^{8}$, storage decisions are given by the following:

$$
\begin{array}{r}
I_{t}=0 \text { if } \beta(1-\delta) E_{t} p_{t+1}<p_{t} \\
0<I_{t}<(1-\delta) I_{t-1}+z_{t} \text { if } \beta(1-\delta) E_{t} p_{t+1}=p_{t} \\
0<I_{t}=(1-\delta) I_{t-1}+z_{t} \text { if } \beta(1-\delta) E_{t} p_{t+1}>p_{t}
\end{array}
$$

As in the standard model, if there is an expected loss of holding storage, as in equation (3), the agent sells grain, which drives the price down ( $p_{t}$ decreases). If there is still an expected loss from storing grain when only one unit of grain remains in the warehouse, the agent sells out his stock and storage is zero, $I_{t}=0$.

\footnotetext{
${ }^{7}$ Note that farmers are seen here as profit-maximizing agents. It implies in particular that consumption is not explicit, as it is in typical household models. Grain storage destined for own consumption is considered to be exogenous and separate from the grain stock that is stored to maximize profits. In support of this assumption, farmers in Burkina Faso typically consume their grain (maize, millet or sorghum) twice a day (the "Tô"), and purchase meat, fish, vegetables, oil or spices as their income and market prices allow. As long as they are net sellers, the amount of grain eaten by farmers is nearly inelastic.

${ }^{8}$ i.e. $I_{t-1}>0$ or $z_{t}>0$. If $I_{t-1}=z_{t}=0$, then $I_{t}=0$
} 
However, if the price decrease due to the sale is such that the agent has not stocked out all of his grainwhen the expected profit of holding grain equals the present profit of selling grain, the agent maintains a strictly positive level of storage (equation (4)). This is also described in the standard model.

The difference between our model and the standard model arises from equation (5). When expected prices are high enough, there is a strictly positive profit from holding stock, and the agent holds his entire stock until the next period. If the agent could purchase grain, price $p_{t}$ would increase until $\beta(1-\delta) E_{t} p_{t+1}=p_{t}$. At this equilibrium, the agent would stop purchasing grain and inequality in equation (5) would never be observed, as in Deaton and Laroque's model. Since the farmer cannot purchase grain, he simply retains the entire stock until $t+1$ and price does not increase in $\mathrm{t}$, so that inequality (5) holds. This is consistent with negative or no skewness in price distribution: storage fails to regulate downward price spikes (equation 5) and stock non-negativity fails to regulate upward spikes (equation 3).

Because of equation (5), the theorems on stationary rational expectations equilibrium proposed by Deaton and Laroque (1992) do not hold in the presence of a liquidity constraint. In this case, the market price is no longer a maximum of two possible definitions (3) and (4). Instead, the actual price may now be inferior to the discounted expected price and moreover, may not converge toward this expected discounted price.

This explains why, contrary to what is observed in international commodity markets by Deaton and Laroque (1992) or Wright (2011) price drops can be at least as strong as price peaks in domestic markets in which farmers and stockholders face liquidity constraints. The conditions required in order to observe the stabilizing effects of storage on volatility as described in the competitive storage model are met less frequently in countries with limited credit availability like Burkina Faso. 


\subsection{Heterogeneous price expectations}

We introduce heterogeneous expectations and analyze how they produce suboptimal storage decisions. Farmers in a village may infer the total amount of stock in the village from their own stock level, and the quality of this inference is likely to vary across farmers. For instance, large-scale farmers are presumably better at inferring the total stock level from their own stock than small scale farmers. Given this heterogeneity in information, it is reasonable to expect that not all farmers can anticipate prices with the same degree of accuracy, and that this impact price expectations and thus storage decisions ${ }^{9}$.

Over a population of $N$ farmers in the village, assume that $n$ farmers' expectations are such that $\beta(1-\delta) E_{t}^{n} p_{t+1} \leq p_{t}$, and $N-n$ farmers' expectations are such that $\beta(1-\delta) E_{t}^{N-n} p_{t+1}>p_{t}$. This can occur, for instance, if $n$ farmers hold a large stock and believe that the $N-n$ farmers hold a greater stock than they actually have, or if the $N-n$ farmers hold little stock and believe that the $n$ farmers have less stock than they actually have. Equation (3) shows that the $n$ farmers sell out their stock if $\beta(1-\delta) E_{t}^{n} p_{t+1}<p_{t}$ after they have sold out and equation (4) shows that they sell some grain if $\beta(1-\delta) E_{t}^{n} p_{t+1}=p_{t}$ before they have sold out. However, since the $N-n$ hold little stock in reality, the price is

9 Although standard models assume that price expectations are formulated based on information about the amount of grain on hand in the household, information about the total amount of grain on hand in the village would arguably be more relevant for formulating correct price expectations. If farmers conceal the true level of stock that they have, each farmer is left with only a belief about the aggregate amount of stock in the village. Furthermore, farmers who have had an abundant harvest would be more likely to believe that other farmers have also had a good harvest and therefore would also be more likely to overestimate total stock in the village. Similarly, these farmers would be less likely to anticipate a resource shortage at the village level for the next period and accordingly, less likely to anticipate a high price of grain in the next period compared to farmers who possess a low stock of grain.

This article is protected by copyright. All rights reserved. 
likely to increase between $t$ and $t+1$, more than the $n$ farmers had anticipated. At $t$, the $n$ farmers underestimate $p_{t+1}$.

Symmetrically, equation (5) shows that the $N-n$ hold their stock from $t$ to $t+1$. If the $n$ hold more stock than the $N-n$ believe they do, the price at $t+1$ is likely to increase less than expected by the $N-n$, and may even decrease. This describes be a price overestimation by the $N-n$.

\section{Heterogeneous price expectations errors}

This section aims to understand how expectation errors influence storage. A price expectation error is defined as the difference between the expected price for $t+1$ and the actual price realized at $t+1, \eta_{t, t+1}=E_{t} p_{t+1}-p_{t+1}$. A price overestimation occurs when $\eta_{t, t+1}>0$ and a price underestimation occurs when $\eta_{t, t+1}<0$.

First order conditions can be written in terms of expectation errors:

$$
\begin{aligned}
& \text { if } \quad \eta_{t, t+1}<\frac{p_{t}}{\beta(1-\delta)}-p_{t+1}, \quad I_{t}=0 \\
& \text { if } \quad \eta_{t, t+1}=\frac{p_{t}}{\beta(1-\delta)}-p_{t+1}, \quad 0<I_{t}<(1-\delta) I_{t-1}+z_{t} \\
& \text { if } \quad \eta_{t, t+1}>\frac{p_{t}}{\beta(1-\delta)}-p_{t+1}, \quad I_{t}=(1-\delta) I_{t-1}+z_{t}>0
\end{aligned}
$$

The interpretation of these conditions rests on the sign of $\eta_{t, t+1}$.

Price overestimation situations, $\eta_{t, t+1}>0$

The effect of a price overestimation differs depending on whether the price decreases or increases less than expected. 
If the price drops or moderately increases between $t$ and $t+1$, such that $\frac{p_{t}}{\beta(1-\delta)}>p_{t+1}$, the optimal choice at $t$ would be to stock out. The actual storage decision at $t$ depends on the size of the error. If the error is small enough as in (6), the farmer stocks out. The expectation error does not produce a storage error. If the error is large enough as in (8) the farmer holds the entire stock, and storage error is maximal.

If the price increase is intermediate, such that $\frac{p_{t}}{\beta(1-\delta)}=p_{t+1}$, the overestimation leads farmers to hold their stock, whereas the optimal decision would have been a partial stock release.

If the price increases sharply between $t$ and $t+1$ (less than expected), such that $\frac{p_{t}}{\beta(1-\delta)}<p_{t+1}$, the optimal decision is to hold their stock, which is also the actual decision. The price overestimation has no consequence in this case.

To summarize, if $I_{t+1}^{*}$ denotes the optimal inventory in $t+1$, that the farmer would have held if he made no error in $t$, the extra-inventory i.e. $I_{t+1}-I_{t+1}^{*}$, is positive or nil in case of a proce overestimation in $t$. A more rigourous and detailed development of different subcases is presented in the appendix online, leading to proposition 1.

Proposition 1. Sufficient conditions for expectation error at $t$ to generate extra inventory at $t+1$ are $\left\{\begin{array}{c}0 \leq \frac{p_{t}}{\beta(1-\delta)}-p_{t+1}<\eta_{t, t+1} \\ p_{t+1}<\beta(1-\delta) E_{t+1} p_{t+2}\end{array}\right.$

The first condition implies that the actual price change is a price decrease or a small increase (compatible with stocking out) whereas the farmer believes in a stronger price increase (incompatible with stocking out); the second condition implies the farmer's 
expectations at $t+1$ do not produce stocking out in $t+1$ (which would suppress the effect of the error).

\section{Price underestimation situations}

In the case of a sufficient price increase between $t$ and $t+1, \beta(1-\delta) p_{t+1}>p_{t}$, the optimal behaviour would be to hold the entire stock from $t$ to $t+1$ (equation 5), i.e. $I_{t+1}^{*}=(1-\delta) I_{t}+z_{t+1}$. We show that underestimating the future price favors lower-thanoptimum stocks or stock-out (proof in the appendix online).

In the case of a price decrease or moderate price increase (compatible with optimal stocking out), the error makes no difference since it does not prevent stocking out.

Proposition 2. Sufficient conditions for expectation error at $t$ to generate underinventory at $t+1$ are $\left\{\begin{array}{c}\eta_{t, t+1}<\frac{p_{t}}{\beta(1-\delta)}-p_{t+1} \leq 0 \\ p_{t+1}<\beta(1-\delta) E_{t+1} p_{t+2}\end{array}\right.$

\subsection{Price expectation errors and carry-over}

Carry-over is defined as the stock that remains on hand at the end of a crop season and before the new harvest is realized, e.g. in October. There are few models based on monthly decisions that are derived from the competitive storage models and that permit carryover of an annual harvest into the following year (Peterson and Tomek, 2005). Frechette (1999) develops a storage model, assuming that the decision to retain carry-over can be a rational decision akin to investing in self-insurance in the case of a bad harvest. We suggest here the alternative explanation that carry-over may result from expectation errors. 
The link between unexpected price drops in the lean season and subsequent carry-over

In general, price declines occur at the time of the harvest or slightly before the harvest, and farmers expect this price drop to happen even if they do not know precisely when it will occur. If farmers could accurately anticipate this drop, our framework suggests that they would sell out their stock before it happens, and carry-over would not exist. However, due to events such as changes in regional supply generated by harvests in neighboring countries, prices can drop before they are expected to. Farmers who do not anticipate this price drop miss the last occasion to sell before the new harvest arrives and further depresses the price of grain.

If the harvest in the village begins at $t+1$, the stock on hand at $t+1$ represents carryover from the previous harvest. Applying proposition 1 to this period we get result 1 .

\section{Result 1. Unexpected price drops occurring before harvest tend to increase carry-over.}

The link between carry-over and post-harvest unexpected price drops

Analyzing the link between carry-over and prices requires market clearing conditions. As in the standard model, we assume that at $t+1$

$$
p_{t+1}=P\left((1-\delta) I_{t}^{N}+z_{t+1}^{N}-I_{t+1}^{N}\right)
$$

where $P($.$) is the inverse demand function. Farmers' expectations of the price in t+1$ can be written as the expected inverse demand function depending on their own inventory and their belief about the inventory of other farmers.

$$
E_{t}^{n} p_{t+1}=E_{t}^{n} P\left((1-\delta)\left(I_{t}^{n}+\hat{I}_{t}^{N-n}\right)+z_{t+1}^{N}-I_{t+1}^{N}\right)
$$

where $\hat{I}_{t}^{N-n}$ is the $n$ farmers' belief about the amount of stock held by the $N-n$. 
We are interested in the case in which the $n$ farmers have stocked out and believe that the $N-n$ farmers have also stocked out. In this case, $E_{t}^{n} p_{t+1}=P\left(z_{t+1}^{N}-I_{t+1}^{N}\right)$ and $\eta_{t}^{t+1}=P\left(z_{t+1}^{N}-I_{t+1}^{N}\right)-P\left((1-\delta) I_{t}^{N-n}+z_{t+1}^{N}-I_{t+1}^{N}\right)>0$. This implies that the existence of carryover held by the $N-n$ produces a price overestimation by the $n$, if the latter ignore this carry-over. In addition, if $p_{t+1}<p_{t}$, this price overestimation is an unexpected price drop (for the $n$ farmers).

\section{Result 2. Greater carry-over favors unexpected price drops after the harvest.}

The empirical relevance of the two above results is tested in Section 4 of this paper.

\section{Empirical strategy}

\subsection{Data on maize price}

SONAGESS (Societe Nationale de Gestion du Stock de Securite) collects maize prices on a weekly basis in 48 markets throughout the country, and publishes monthly prices. We use a subset of 33 series of maize prices with no discountinuities over the 2004-2014 period. Monthly prices have been deflated using the Burkinabe Consumer Price Index obtained from the INSD (Institut National des Statistiques Demographiques). The evolution of maize producer real prices is represented in Figure 1 for three markets: one market in a surplus area, one in a deficit area, and a third in the capital city of Ouagadougou. Grain prices are higher in deficit areas than in surplus areas and follow a seasonal dynamic, with maximum prices occurring between July and September, corresponding to the lean season in Burkina Faso, and minimum prices occurring between October and December, corresponding to the harvest season. In each of the three markets studied, price peaks were quite pronounced in 2005 , 2008, 2012 and to a lesser extent in 2009. In these years, price peaks were mainly associated with poor harvests, which were related to events such as insect infestations (2005), episodes 
of drought (2009 and 2012), and international price spikes (2008 and 2012). Price rises are less accentuated following good harvest years (as in 2013), and even less so in surplus areas. This indicates that in these surplus areas, farmers are more likely to have stocks left over to sell during the lean season, which limits price spikes. Furthermore, although the magnitude of price spikes is somewhat greater than the magnitude of price drops, price drops are clearly present, contrarily to what is frequently observed (Deaton and Laroque, 1992) ${ }^{10}$.

Figure 1: Real maize prices in Burkina Faso, 3 markets, 10 years (SONAGESS data)

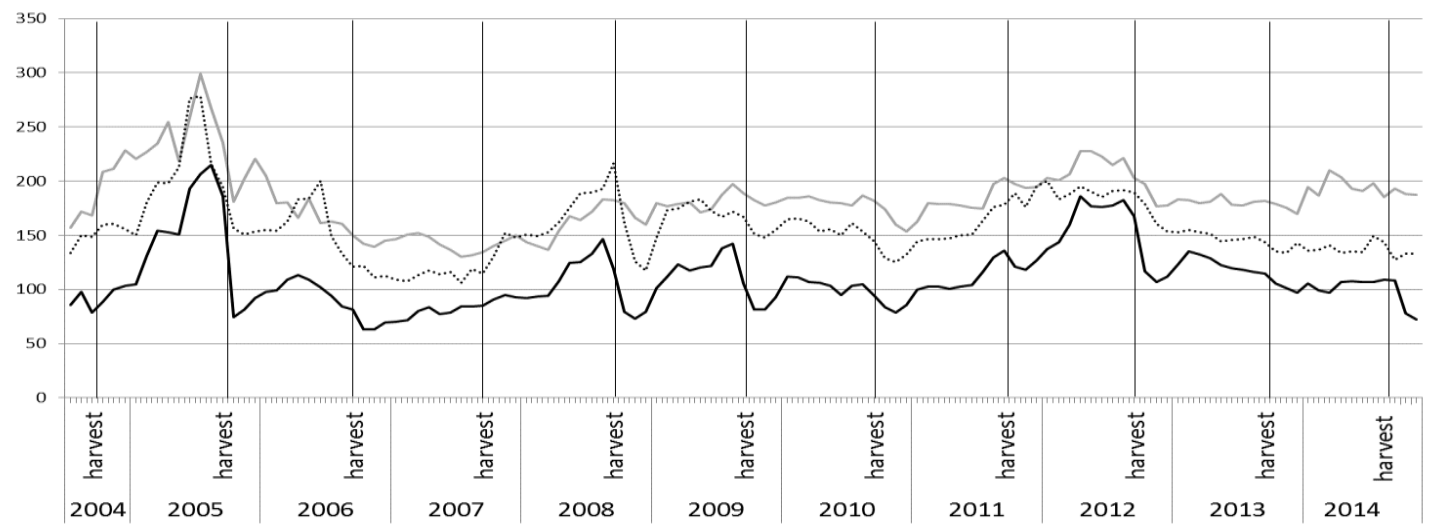

_ Dori (remote market, deficit area) ….... Sankaryare (City-capital market)

- Solenzo (remote market, surplus area)

\subsection{Data on maize production and storage}

The Burkinabe Ministry of Agriculture has been collecting data on agricultural production through the implementation of a panel rural household survey since 1992. Once a year, an average of 4500 rural households are interviewed and their agricultural production is measured. The panel survey is conducted using a two-stage stratified randomized design.

10 see notably the figure on annual international sugar price between 1930 and 1990

This article is protected by copyright. All rights reserved. 
First, villages are randomly chosen in each province, where the relative number of villages per province is dependent on the relative population of each the 48 provinces in Burkina Faso. In the second stage, five households are randomly selected in each of the selected villages. This two-stage process ensures that the surveyed households are representative of rural households both at the province and national levels, which justifies our use of aggregate province-level data to analyze storage behaviors. The storage data we use comes from a subset of 3160 households, located across 33 different provinces with complete price series. From this subset, we also make use of data on annual maize production as well as maize carry-over, which is defined as the amount of on-farm maize stock remaining when the next harvest season arrives following the end of the lean season. Individual data have been aggregated at the province level corresponding to the 33 markets analyzed. Carry-over is measured once a year for 33 different provinces over 8 years. Prices are measured once a month for the 33 different provinces over 10 years.

The final panel database is composed of 33 markets for which we have yearly carryover data over 8 years (2005 to 2012), and price data over 10 years (2004-2013). Descriptive statistics on maize price, storage, and production in each of the 33 markets are given in Table 8 in the appendix.

\subsection{Measuring volatility}

In recent literature, price volatility is defined in this paper as the unpredictable component of price variations. Predictable price variations, like price seasonality or price trend, are not part of price volatility. The empirical measurement of volatility requires assumptions regarding the information available to agents and their ability to anticipate prices. A commonly used model to distinguish the predictable and the unpredictable part of price variation is the AutoRegressive Conditional Heteroskedastic (ARCH) model (Shively, 1996; Barrett, 1997; Gilbert and Morgan, 2010; Apergis and Rezitis, 2003; Serra and Gil, 2013; Maître d'Hôtel, 
Le Cotty, and Jayne, 2013). A mean equation provides the predictable price at $t$ conditional on information available at $t-1$ and a conditional variance of the error term of the mean equation provides a measure of price volatility that changes with $t$.

Because we have one price series for each market, we estimate a common specification of such model for each price series, based on a unique ARCH structure. The ARCH model structure is as follows.

$$
\begin{aligned}
& P_{m t}=\beta_{0}+\beta_{1} P_{m t-1}+\sum_{i=1}^{11} \beta_{i} D_{i}+\varepsilon_{m t} \quad \varepsilon_{m t}: \mathrm{N}\left(0, h_{m t}\right) \\
& h_{m t}=\alpha_{0}+\alpha_{1} \varepsilon_{m t-1}^{2}+v_{m t} \quad v_{m t}: \mathrm{N}(0, \sigma)
\end{aligned}
$$

where the subscript $m$ denotes the market index.

Equation (11) is the mean equation that determines the deflated producer price of maize as a 1-order autoregressive process. $D_{i}$ is a monthly dummy variable taking the value 1 for month $i$. A 1-order autoregression was selected after testing the number of significant periods in each individual market. While introducing $P_{t-2}$ and $P_{t-3}$ in the model is significant for some markets, we elect to use a unique and parsimonious model structure for each market in order to facilitate the comparability of predicted prices across markets. A trend variable was tested and rejected due to low statistical significance. Equation (12) determines the conditional variance of the error term $\varepsilon_{m t}$ as a function of the shock in the previous period and confirms the significant $\mathrm{ARCH}$ nature of the price process in 20 out of the 33 villages. In the 13 remaining villages, the price process is autoregressive with homoscedastic variance ${ }^{11}$.

\footnotetext{
${ }^{11}$ One can question whether the ARCH model accurately captures the unpredictable component of price changes for farmers. If farmers are able to make better price forecasts than our ARCH model, some of what we consider to be unexpected price shifts would, in fact, be expected. This would lead
} 


\subsection{Measuring unexpected price drops and spikes}

We conduct the estimations above for each of the 33 markets so as to obtain 33 series of price volatility. Next, we segregate each series into two: the series of conditional variances for negative unexpected price shocks and the series of conditional variances for positive unexpected price shocks. We then calculate the average variance for each series over a period of time varying from one month to 12 months in order to examine the robustness of the relationship between volatility and carryover. The occurrence of positive price spikes in market $m$, for year $j$ between month $\tau_{0}$ and month $\tau_{1}$ is calculated as follows:

$$
h_{m j \tau_{0} \tau_{1}}^{+}=\frac{1}{\tau_{1}-\tau_{0}} \sum_{t=\tau_{0}}^{\tau_{1}} \hat{h}_{m t}^{+}=\hat{\alpha}_{0}+\frac{\hat{\alpha}_{1}}{\tau_{1}-\tau_{0}} \sum_{\substack{t=\tau_{0} \\ \varepsilon_{m t}>0}}^{\tau_{1}} \varepsilon_{m t-1}^{2}
$$

A similar calculation is made for $h_{m j \tau_{0} \tau_{1}}^{-}$, the occurrence of unexpected price drops in market $m$ for year $j$ between month $\tau_{0}$ and month $\tau_{1}$.

\subsection{Estimating the link between unexpected price drops during the lean season and carry-over at the end of the lean season}

Carry-over is empirically specified by

$$
\chi_{m j}=\gamma_{0}+\gamma_{1} \chi_{m j-1}+\gamma_{2} h_{m j \tau_{0} \tau_{1}}^{-}+\gamma_{3} y_{m j-1}+\varepsilon_{m j} \quad \varepsilon_{m j}: \mathrm{N}\left(0, \sigma_{\varepsilon}\right) \quad m=1, \ldots, 33 \quad j=2005, \ldots, 2012
$$

to an overestimation of expectation errors. Although possible, we do not find this case very likely because the ARCH model is known to make accurate forecasts. A more likely mismatch occurs if the model makes better forecasts than farmers, leading us to underestimate expectation errors. In the appendix online, we provide a robustness check using a coefficient of variation as a measure of price variation that includes seasonal variations and trend, and which produces consistent results. This confirms that most price shifts are unpredictable for some farmers. The ARCH model residuals should be interpreted as a measure of what is unpredictable for all farmers and the coefficient of variation includes fluctuations that are unpredictable for the less informed farmers only. 
Where $\chi_{m j}$ is the average amount of carry-over in region $m$ at the end of the lean season of calendar year $j$ and $y_{m j-1}$ is the grain harvest at the end of calendar year $j-1$.

According to result 1, we expect carry-over to increase with unexpected price drops during the lean season, when prices are expected to reach their annual peak, that is $\gamma_{2}>0$ for $\tau_{0}$ varying from November of year $j-1$ to October of year $j$ and $\tau_{1}$ varying from September to October of year $j$. The variable summarizing unexpected price drops $h_{m j \tau_{0} \tau_{1}}^{-}$is measured during the period preceding the carry-over. Since no theoretical prediction exists regarding the length of the period, we test different lengths from one month to one year. The fact that this explanatory variable corresponds to the period preceding the measurement of carry-over does not guarantee a causal link between the two when these measures are correlated (Bellemare, 2015). In a village of more educated farmers, for example, strategic stock management leading to optimal carry-over decisions as well as the absence of expectation errors could both result from high education levels. In this case, education could simultaneously be the cause of no carry-over and no expectation error. It is often argued that the fixed effects in a panel estimation can theoretically control for this type of simultaneous unobserved causality (e.g. the quality of information), but it is also arguable that this only reduces endogeneity. Education, for instance, is not necessarily fixed.

Our approach consists in using several measures of expectation error to test the strength of the correlation between unexpected price drops that occur between the harvest and lean season, and the carry over at the end of the lean season.

\subsection{Estimating the relationship between post-lean season carry-over and post-harvest} unexpected price drops

The empirical specification for the variance of unexpected negative price shocks is given by 


$$
\begin{aligned}
& h_{m j \tau_{0} \tau_{1}}^{-}=\rho_{0}+\rho_{1} h_{m j-1 \tau_{0} \tau_{1}}^{-}+\rho_{2} \chi_{m j}+\rho_{3} y_{m j-1}+\eta_{m j} \quad \eta_{m j}: \mathrm{N}\left(0, \sigma_{\eta}\right) \\
& m=1, \ldots, 33 \quad j=2005, \ldots, 2012
\end{aligned}
$$

Result 2 predicts that the occurrence of unexpected price drops around the harvest season increases with the amount of carry-over that remains after the end of the previous lean season, that is, $\rho_{2}>0$ for $\tau_{0}$ varying between September and November and $\tau_{1}$ varying between October and March.

Both panel equations ${ }^{12}$ are estimated using the generalized moments method following the Arellano and Bover/ Blundell and Bond procedure with predetermined variables (Arellano and Bover, 1995; Blundell and Bond, 1998) ${ }^{13}$. The dynamic panel procedure generates moment conditions using lagged values of the dependent variable and the predetermined variables with first-differences of the disturbances. Because the autoregressive process is persistent, we must obtain additional moment conditions in which the lagged differences of the dependent variable are used as instruments (Arellano and Bover, 1995; Blundell and Bond, 1998). Lagged production and lagged prices are used as predetermined variables, and the dummy variables of fixed market effects are used as exogenous variables. Table 9 in the appendix online describes the volatility variables for the 33 markets we analyse.

\section{Results}

\subsection{Price general characteristics}

\footnotetext{
${ }^{12}$ Our panel may exhibit substantial cross-sectional dependence (equation (16)), which could arise due to the presence of common price shocks and spatial dependence between different markets. We tested for the existence of such dependent price dynamics between markets in our panel data models: the Friedman test rejects the existence of cross sectional dependence between the price dynamics in our different markets, both for negative and positive volatility models.

${ }^{13}$ Price series stationarity is verified with an augmented Dickey Fuller test
} 
As observed elsewhere, our price series exhibit a positive skewness, but the average coefficient is much lower in our case (0.25) than in Deaton and Laroque (1.18 for maize), implying that local monthly prices in rural areas may also be asymmetric, though to a lower extent. Furthermore, for post-harvest periods (November-May), skewness is negative in 15 of the 33 villages, indicating huge price drops that challenge the classical asymmetric stylized fact.

Kurtosis is negative in more than half of marketplaces, which indicates a flatter distribution than in the normal distribution (i.e. greater price fluctuations). Average kurtosis is -0.21 in our price series (versus +2.48 in Deaton and Laroque).

Table 1: Average characteristics of price distributions in 33 market (SONAGESS data)

\begin{tabular}{cccccccc}
\hline & $\begin{array}{c}\text { Obs per } \\
\text { market }\end{array}$ & $\begin{array}{c}\text { Average } \\
\text { price }\end{array}$ & $\begin{array}{c}\text { Average } \\
\text { std }\end{array}$ & $\begin{array}{c}\text { Average } \\
\text { skewness }\end{array}$ & $\begin{array}{c}\text { Average } \\
\text { kurtosis }\end{array}$ & $\begin{array}{c}\text { Markets } \\
\text { with } \\
\text { negative } \\
\text { skewness }\end{array}$ & $\begin{array}{c}\text { Markets } \\
\text { with } \\
\text { negative } \\
\text { kurtosis }\end{array}$ \\
\hline complete series & 121 & 134,87 & 31,39 & 0,25 & $-0,21$ & 3 & 15 \\
\hline $\begin{array}{c}\text { pre-harvest } \\
\text { season }\end{array}$ & 52 & 140,52 & 36,36 & 0,33 & $-0,40$ & 4 & 27 \\
$\begin{array}{c}\text { Post-harvest } \\
\text { season }\end{array}$ & 69 & 130,58 & 26,32 & 0,11 & 0,17 & 15 & 14 \\
\hline
\end{tabular}

\subsection{Price volatility}

The mean equation in the $\mathrm{ARCH}$ model shows that prices follow an autoregressive process with large and significant monthly autocorrelation, and that pre-harvest prices are significantly higher than prices during the rest of the year, while post-harvest prices are significantly lower. These results are consistent with those of Shively (1996); Barrett (1997); and Karanja, Kuyvenhoven, and Moll (2003). For a deflated price index with a mean of 
approximately 100 (depending on the markets) the seasonal average difference between high and low prices is around 10 .

Figure 2 depicts the annual evolution of average prices and average unexpected price drops and spikes. Month 1 denotes January, etc. This evolution illustrates that, even after price series are deseasonalized, the frequency of large positive price shocks is not the same throughout the year. Prices are on average higher between June and August and unexpected price shocks occur most frequently in July. Conversely, negative price shocks occur mainly in October, when prices are lower. Note that the harvest period (October-November) is both a period of price drops and price spikes, meaning that there are on average more unexpected drops and peaks during these months. Unexpected peaks could occur due to low harvests, generating price increases earlier than usual, whereas unexpected price drops could occur due to unobserved carry-overs. Figure 2 also illustrates that carry-overs measured before the harvest in September may impact the frequency of unexpected price drops as long as these carry-overs increase sales.

Descriptive statistics on average volatilities for the 33 markets we study are given in the appendix online.

Figure 2: Average unexpected price drops and spikes over the year in Burkina Faso, 33 markets, 10 years (from SONAGESS data)

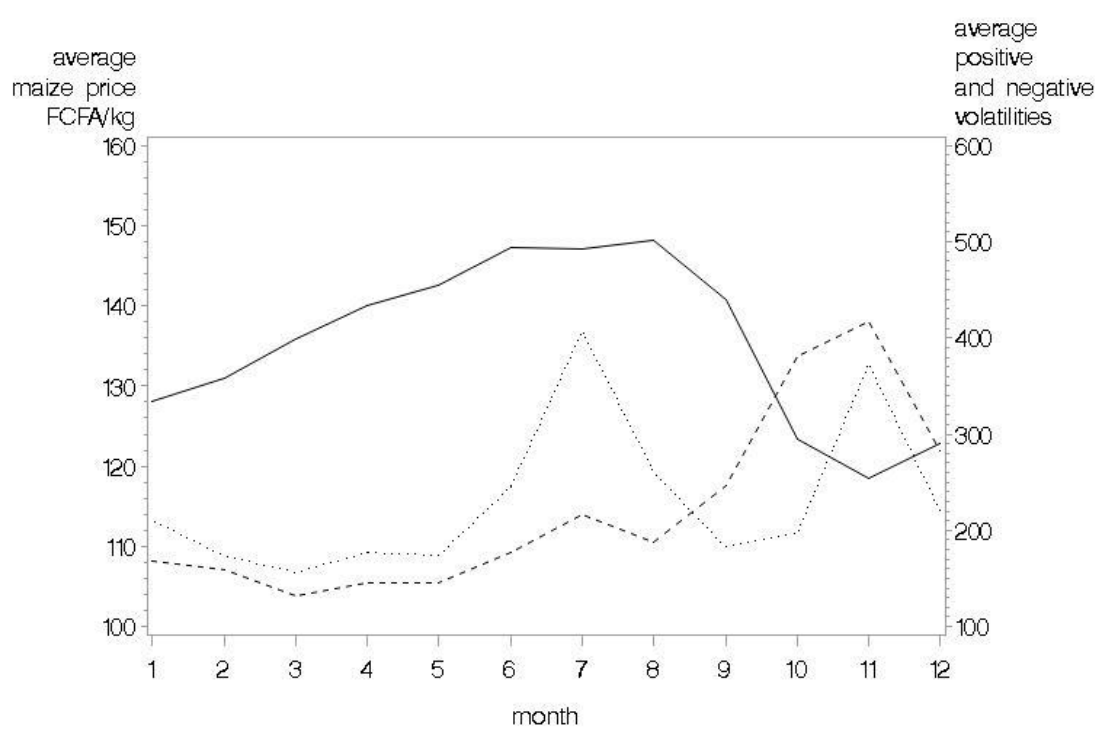


The frequency of unexpected price drops and spikes within a year is depicted in Figure 3 below.

Figure 3: Unexpected price drops and spikes within a year in Burkina Faso, 33 market places, 10 years (from SONAGESS data)

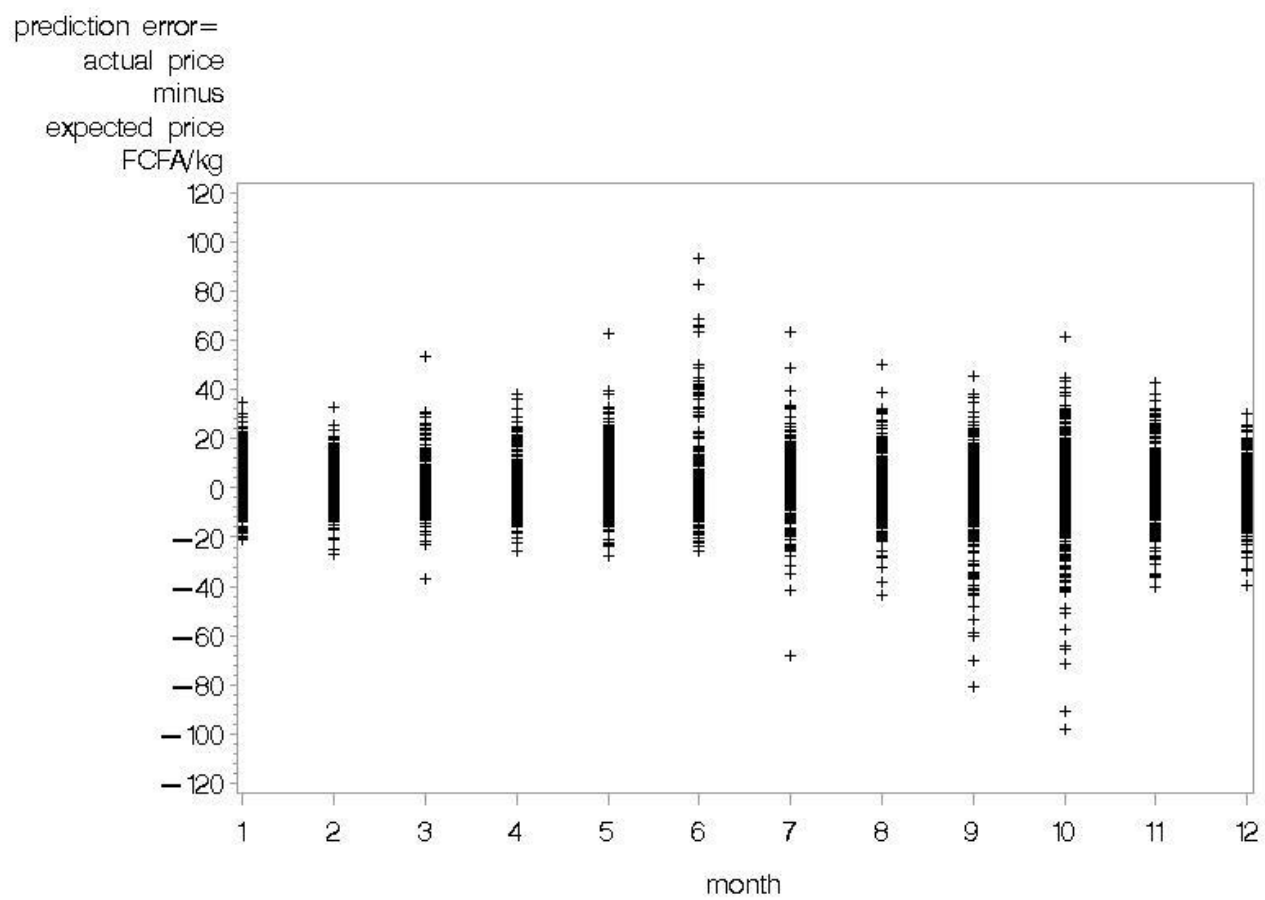

This article is protected by copyright. All rights reserved. 


\subsection{The link between volatility and subsequent carry-over}

The model predicts that carry-over at the end of the farming year should be zero if no unpredicted price drop has preceded the harvest. If many significant unexpected price drops have occurred before harvest, it is likely that several farmers have missed the opportunity to sell their stock on time, and thus, the amount of carry-over should be large (result 1). This is confirmed by the estimation presented in Table 2, which indicates that not all farmers who still have stock during the lean season anticipate price drops correctly, causing some to miss their chance to sell out before the price drop occurs. The 8 different specifications correspond to different time frames over which price volatility is measured. Specification [1] covers one yearly cycle, from the post-harvest season in November to October of the following year. Specifications [2] to [8] consider the lean season specifically. Unexpected price drops occurring during the lean season (July-September, specification [4] in Table 2) tend to increase the amount of carry-over at the $5 \%$ level, as is predicted (result 1). This feature holds for average annual price drops (specification [1]) and is even stronger for price drops observed during the lean season, i.e. the July-September period (specifications [4], [6] and [7]). Excluding September from the observed period, this result does not hold, indicating that unexpected price drops in September are critical in favoring carry-over (specifications [2], [3] and [5] in Table 2).

This article is protected by copyright. All rights reserved. 
Table 2: Unexpected price drops during the lean season and carry-over at the end of the lean season

\begin{tabular}{|c|c|c|c|c|c|c|c|c|}
\hline & {$[1]$} & [2] & [3] & [4] & [5] & [6] & [7] & [8] \\
\hline Lagged carry- & $0.19 * *$ & $0.42 * *$ & $0.15^{* *}$ & 0.19 & $0.10^{* *}$ & 0.09 & 0.10 & 0.26 \\
\hline over & * & $*$ & * & & $*$ & & & \\
\hline $\begin{array}{l}\text { Unexpected } \\
\text { price drops }\end{array}$ & $0.28 * *$ & 0.38 & 0.57 & $1.13^{* *}$ & 0.33 & $0.96 * *$ & $1.33^{*}$ & -0.02 \\
\hline Harvest & $\begin{array}{c}0.13^{* *} \\
*\end{array}$ & $0.06 *$ & $0.22 *$ & $0.06 * *$ & $0.10 * *$ & $0.19 * * *$ & $\begin{array}{c}0.23 * * \\
*\end{array}$ & 0.06 \\
\hline Constant & -36.68 & -60.43 & -214.66 & $\begin{array}{c}113.88 \\
*\end{array}$ & 123.39 & $-192.05^{*}$ & -279.28 & 10.85 \\
\hline Obs & 264 & 264 & 264 & 264 & 264 & 264 & 264 & 264 \\
\hline $\begin{array}{l}\text { Period used } \\
\text { for price drops } \\
\tau_{0}-\tau_{1}\end{array}$ & $\begin{array}{c}\text { Nov- } \\
\text { Oct }\end{array}$ & Jul & $\begin{array}{l}\text { Jul- } \\
\text { Aug }\end{array}$ & $\begin{array}{l}\text { Jul- } \\
\text { Sept }\end{array}$ & Aug & $\begin{array}{l}\text { Aug- } \\
\text { Sept }\end{array}$ & Sept & Oct \\
\hline
\end{tabular}

When significant, carry-over is positively correlated with previous carry-over and the previous harvest.

The relationship between unexpected price spikes and subsequent carry-over does not appear to be significant (see table 5 in the appendix online).

\subsection{The link between carry-over and subsequent volatility}

The impact of carry-over on unexpected price drops is presented in Table 3 and Table 4 below, in which the different specifications correspond to different time periods over which price drops are measured.

As in our theoretical development (result 2), carry-over tends to favor episodes of unexpected price drops throughout the following year (specification [1] in table 3), and this 
feature is stronger when considering shorter post-harvest periods from November to March (specifications [3] to [7]). However, this correlation tends to disappear as time progresses following the harvest (Table 4).

Another observation is that the harvest has either zero or a negative correlation with subsequent unexpected price drops. An abundant harvest certainly drives the price of grain down, but it appears that most of this effect is expected by farmers, implying that abundant harvests may not increase the occurrence of unexpected price drops. One potential interpretation of this finding is that, in a good harvest year, everyone knows the level of global production and resulting price drops are better anticipated, while in a poor harvest year, it is more difficult for everyone to judge the global harvest amount and thus massive unexpected price drops may occur ${ }^{14}$.

Table 3: Pre-harvest carry-over and post-harvest unexpected price drops

\begin{tabular}{|c|c|c|c|c|c|c|c|}
\hline & [1] & [2] & [3] & [4] & [5] & {$[6]$} & [7] \\
\hline $\begin{array}{c}\text { Lagged } \\
\text { unexpected } \\
\text { price drops }\end{array}$ & 0.13 & -0.12 & $-0.14 * *$ & $-0.10 * *$ & $-0.09 *$ & 0.00 & 0.07 \\
\hline Carry-over & $0.02 * *$ & 0.09 & $0.12 * * *$ & $0.13 *$ & $0.11 * *$ & $0.11 * *$ & $0.06 *$ \\
\hline Harvest & $-0.03 *$ & 0.01 & $-0.12 * *$ & $-0.07 * *$ & -0.05 & -0.04 & -0.03 \\
\hline Constant & $\begin{array}{c}235.38 * \\
*\end{array}$ & 273.63 & $\begin{array}{c}588.70^{*} \\
*\end{array}$ & $\begin{array}{c}430.85^{*} \\
*\end{array}$ & $\begin{array}{c}368.17 * \\
*\end{array}$ & $\begin{array}{c}304.92 * \\
*\end{array}$ & $269.24 * *$ \\
\hline Obs & 264 & 264 & 264 & 264 & 264 & 264 & 264 \\
\hline $\begin{array}{l}\text { Period used } \\
\text { for price } \\
\text { drops }\end{array}$ & $\begin{array}{c}\text { Nov- } \\
\text { Oct }\end{array}$ & Nov & $\begin{array}{l}\text { Nov- } \\
\text { Dec }\end{array}$ & $\begin{array}{c}\text { Nov- } \\
\text { Jan }\end{array}$ & $\begin{array}{c}\text { Nov- } \\
\text { Fev }\end{array}$ & $\begin{array}{l}\text { Nov- } \\
\text { Mars }\end{array}$ & $\begin{array}{l}\text { Nov- } \\
\text { Avr }\end{array}$ \\
\hline
\end{tabular}

\footnotetext{
${ }^{14}$ A robustness test is presented in Table 7 in the appendix online, where volatility is measured with a coefficient of variation of price.
} 
Table 4: Pre-harvest carry-over and post-harvest unexpected price drops. Continued.

\begin{tabular}{ccccccc}
\hline & {$[8]$} & {$[9]$} & {$[10]$} & {$[11]$} & {$[12]$} & {$[13]$} \\
\hline $\begin{array}{c}\text { Lagged } \\
\text { unexpected price } \\
\text { drops }\end{array}$ & -0.24 & 0.01 & 0.02 & 0.11 & -0.14 & -0.25 \\
Carry-over & 0.03 & 0.15 & 0.03 & -0.28 & 0.01 & 0.16 \\
Harvest & $-0.16^{* *}$ & -0.12 & -0.01 & 0.02 & 0.01 & 0.00 \\
Constant & $579.20^{* * *}$ & $362.98^{* *}$ & $240.88^{* * *}$ & $142.98^{* * * *}$ & $186.92 * * *$ & $223.69 * * *$ \\
\hline Obs & 264 & 264 & 264 & 264 & 264 & 264 \\
\hline $\begin{array}{c}\text { Period considered } \\
\text { for price drops }\end{array}$ & Dec & Dec-Jan & Dec-Feb & Jan & Jan-Feb & Feb \\
\hline
\end{tabular}

The relationship between carry-over and subsequent unexpected price spikes does not appear significant (see table 6 in the appendix online).

\section{Conclusion}

Most of the research on the influence of storage decisions on price volatility has focused on either public storage or speculative storage. In this paper, we develop a model that analyses the effect of farmers' storage decisions and relies on two assumptions: that farmers operate under liquidity constraints and that their price expectations are heterogeneous. We develop a theoretical model showing that the errors they make in anticipating prices increase the occurrence of extra carry-over and the frequency of unexpected price drops. To check the empirical relevance of this model, we focus on maize price volatility in Burkina Faso, and we analyze the relationship between the levels of stock held by farmers and price volatility levels observed in 33 local markets over the 2004-2014 period. We differentiate between 
unexpected price drops and spikes and provide empirical evidence that carry-overs are correlated with unanticipated price drops during the previous lean season and that this carryover increases the frequency of unexpected price drops at the beginning of the subsequent season.

This does not constitute empirical proof of a causal relationship between expectations errors and volatility, but our empirical findings are consistent with the claim that farmers do, in fact, make expectation errors and that these errors are correlated with subsequent carryover, and that this carry-over is correlated with subsequent price volatility.

This suggests that some of the price volatility observed in rural markets is produced locally, as a result of the behaviour of those farmers who do not have perfect information on available stocks.

Our model and empirical results support the implementation of policy measures that favor market integration and improved information dissemination. If markets were better integrated, information on existing stocks in the village would not be of such importance, implying that single transactions in villages would not have the capacity to produce price collapses that lead to extra carry-overs, grain depreciation, and price volatility. We offer two suggestions regarding ways in which markets could be better integrated. First, the physical integration of villages could be improved by reducing transport costs through the building of asphalt roads and by supporting greater sharing of information between villages. When a trader enters a village and offers a low price, farmers tend to accept it, especially since they generally ignore prices in other villages given that market access to these villages is difficult. Improved market access should not decrease expectation errors regarding stocks, however, it should reduce their impact on price volatility. Second, unexpected post-harvest price drops could be mitigated through the use of policies that encourage on-farm storage just after the 
harvest period in order to smooth both post-harvest price drops and extreme price increases at the end of the lean season. Given the liquidity constraints that push farmers to sell much of their grain during the harvest period, this is a challenging endeavor in the context of developing countries. These constraints could be eased by subsidizing village storage infrastructures and instituting measures that facilitate greater farmer access to credit. Systems of inventory credit that are currently being developed in Burkina Faso, Ghana, Mali and Niger allow farmers access to credit after the harvest without having to sell their stock at a low price. These systems favor longer storage periods and a reduction in sharp post-harvest price drops, and constitute an interesting issue for future applied research on volatility.

\section{References}

Apergis, N., A. N. Rezitis. 2003. Agricultural Price Volatility Spillover Effects: The Case Of Greece. European Review of Agricultural Economics, 30(3), 389-406.

Arellano, M., and O. Bover. 1995. Another look at the instrumental variable estimation of error-components models. Journal of econometrics, 68(1), 29-51.

Barrett, C. 1997. Liberalization and food price distributions: ARCH-M evidence from Madagascar. Food Policy, 22(2), 155-173.

Bellemare, M. F., and C. B. Barrett. 2006. An ordered Tobit model of market participation: Evidence from Kenya and Ethiopia. American Journal of Agricultural Economics, 88(2), 324-337.

Berg, E. 2016. Commodity Market Dynamics and Price Volatility: Insights from Dynamic Storage Models. Proceedings in Food System Dynamics, pp. 6-16. 
Blundell, R., and S. Bond. 1998. Initial conditions and moment restrictions in dynamic panel data models. Journal of econometrics, 87(1), 115-143.

Bobenrieth, E., B. Wright, and D. Zenz .2013. Stocks-to-use ratios and prices as indicators of vulnerability to spikes in global cereal markets. Agricultural Economics, 44, 1-10.

Branch, W. A. 2004. The theory of rationally heterogeneous expectations: evidence from survey data on inflation expectations. The Economic Journal, 114(497), 592-621.

Cafiero, C., E. Bobenrieth, J. Bobenrieth, and W. Wright. 2011. The empirical relevance of the competitive storage model. Journal of Econometrics, 162, 44-54.

Chavas, J.-P. 2000. On information and market dynamics: the case of the US beef market. Journal of Economic Dynamics and Control, 24(5), 833-853.

De Janvry, A., M. Fafchamps, and E. Sadoulet. 1991. Peasant household behaviour with missing markets: some paradoxes explained. The Economic Journal, 101(409), 14001417.

Deaton, A., and G. Laroque. 1992. On the Behaviour of Commodity Prices. Review of Economic Studies, 59(1), 1-23.

Fackler, P. L., and M. J. Livingston. 2002. Optimal Storage by Crop Producers. American Journal of Agricultural Economics, 84(3), 645-659.

Fafchamps, M. 1992. Cash crop production, food price volatility, and rural market integration in the third world. American Journal of Agricultural Economics, 74(1), 90-99.

Femenia, F. 2015. The effects of direct storage subsidies under limited rationality: a general equilibrium analysis. Agricultural Economics, 46(6), 715-728. 
Frechette, D. 1999. Stock-outs and supply response estimation under rational expectations. European Review of Agricultural Economics, 26(1), 59-77.

Gilbert, C., and W. Morgan. 2010. Food price volatility. Philosophical Transactions of the Royal Society, 365, 3023-3034.

Grandmont, J.-M. 1998. Expectations formation and stability of large socioeconomic systems. Econometrica, pp. 741-781.

Gustafson, R. 1958. Carryover levels for grains: A method for determining amounts that are optimal under specified conditions. Discussion paper, USDA.

Hommes, C. 2011. The heterogeneous expectations hypothesis: Some evidence from the lab. Journal of Economic dynamics and control, 35(1), 1-24.

Jayne, T., R. Myers, and J. Nyoro. 2008. The effects of NCPB marketing policies on maize market prices in Kenya. Agricultural Economics, 38, 313-325.

Kazianga, H., and C. Udry. 2006. Consumption smoothing? Livestock, insurance and drought in rural Burkina Faso. Journal of Development Economics, 79(2), 413-446.

Key, N., E. Sadoulet, and A. De Janvry. 2000. Transactions costs and agricultural household supply response. American journal of agricultural economics, 82(2), 245-259.

Maître d'Hôtel, E., T. Le Cotty, and T. Jayne. 2013. Trade Policy Inconsistency and Maize Price Volatility: An ARCH Approach in Kenya. African Development Review, 25(4), $607-620$.

Mitra, S., and J.-M. Boussard. 2012. A simple model of endogenous agricultural commodity price fluctuations with storage. Agricultural Economics, 43(1), 1-15. 
Muth, J. F. 1961. Rational expectations and the theory of price movements. Econometrica: Journal of the Econometric Society, pp. 315-335.

Park, A. 2009. Risk and household grain management in developing countries. The Economic Journal, 116(514), 1088-1115.

Peterson, H. H., and W. G. Tomek. 2005. How much of commodity price behavior can a rational expectations storage model explain? Agricultural Economics, 33(3), 289-303.

Saha, A., and J. Stroud. 1994. A Household Model of On-Farm Storage Under Price Risk. American Journal of Agricultural Economics, 76(3), 522-534.

Serra, T., and J. M. Gil. 2013. Price volatility in food markets: can stock building mitigate price fluctuations? European Review of Agricultural Economics, 40(3), 507-528.

Shively, G. 1996. Food price variability and economic reform: An ARCH approach for Ghana. American Journal of Agricultural Economics, 78, 126-136.

Stephens, E. C., and C. B. Barrett. 2011. Incomplete Credit Markets and Commodity Marketing Behaviour. Journal of Agricultural Economics, 62(1), 1-24.

Wright, B. 2011. The Economics of Grain Price Volatility. Applied Economic Perspectives and Policy, 33(1), 32-58.

This article is protected by copyright. All rights reserved. 